\title{
Commentary \\ Causes of a high physiological dead space in critically ill patients
} Peter D Wagner

Division of Physiology, Department of Medicine, University of California at San Diego, 9500 Gilman Drive, 0623A, La Jolla, CA 92093-0623, USA

Corresponding author: Peter D Wagner, pdwagner@ucsd.edu

Published: 14 May 2008

Critical Care 2008, 12:148 (doi:10.1186/cc6888)

This article is online at http://ccforum.com/content/12/3/148

(C) 2008 BioMed Central Ltd

See related research by Niklason et al., http://ccforum.com/content/12/2/R53

\begin{abstract}
Since around 1950, physiological dead space-the difference between arterial and mixed expired $\mathrm{pCO}_{2}$ (partial pressure of carbon dioxide) divided by the arterial $\mathrm{pCO}_{2}$-has been a useful clinical parameter of pulmonary gas exchange. In the previous issue of Critical Care, Niklason and colleagues remind us that physiological dead space, while easily measured, consolidates potentially very complex physiological derangements into a single number. The authors show how shunts raise arterial $\mathrm{pCO}_{2}$, thereby increasing dead space, and how changes in other variables such as cardiac output and acid/base state further modify it. A solid understanding of respiratory physiology is required to properly interpret physiological dead space in the critically ill.
\end{abstract}

In the previous issue of Critical Care, Niklason and colleagues [1] use computer modeling to point out that blood flowing through unventilated regions of the lung (a shunt) will increase arterial partial pressure of carbon dioxide $\left(\mathrm{pCO}_{2}\right)$ if ventilation remains constant. This will increase the calculated physiological dead space accordingly (above that normally present due to the volume of air in the conducting airways). They also show that the increase in $\mathrm{pCO}_{2}$ can be avoided by even modest increases in total alveolar ventilation (although the calculated dead space will remain elevated). While this is not an entirely novel discovery (West [2] performed very similar calculations in 1969 as did Mecikalski and colleagues [3] in 1984), it is well worth having Niklason and colleagues remind us that physiological dead space not only can be caused by the development of regions with a high ventilation/ perfusion ratio $\left(\dot{V}_{A} / \dot{Q}\right)$, but also can come from areas of low $\dot{\mathrm{V}}_{\mathrm{A}} / \mathrm{Q}$ and a shunt. After all, physiological dead space is simply the difference between arterial and mixed expired $\mathrm{pCO}_{2}$ divided by the arterial $\mathrm{pCO}_{2}$. Thus, any gas exchange abnormality has the potential to increase dead space.

Some high-level perspective may be useful. First, it should be remembered that, since introduced by Riley and Cournand
[4] more than 50 years ago, physiological dead space is a virtual concept wherein the lung is conceived as a twocompartment organ in which one compartment is normal and the other is completely unperfused. Physiological dead space, then, is the percentage of the tidal volume that must be distributed to the alveolus that is completely unperfused (and which thus delivers no $\mathrm{CO}_{2}$ to the expired gas) to account for the difference between measured arterial and mixed expired $\mathrm{pCO}_{2}$. Physiological dead space in actual patients may be increased even when no alveoli are completely unperfused-as is the case here in the presence of a shunt. It is useful as a general parameter quantifying gas exchange disturbances but must not be overinterpreted as necessarily implying the existence of unperfused alveoli.

Second, as Niklason and colleagues show, the relationship between shunt and physiological dead space is nonlinear, especially when shunts are high. A shunt of $20 \%$ of the cardiac output increases dead space by just $5 \%$, a shunt of $40 \%$ raises it to approximately $11 \%$, but a shunt of $60 \%$ produces a dead space of about $20 \%$. This is because basic mass balance considerations show that the increase in arterial $\mathrm{pCO}_{2}$ caused by a shunt depends on the factor QS/(100 - QS), where QS is the percentage shunt. Thus, for $\mathrm{CO}_{2}$ exchange, the importance of shunts of less than approximately $30 \%$ is not great, but as shunts approach and exceed $50 \%$, the potential for hypercapnia increases rapidly.

Third, very modest increases in alveolar ventilation can return the arterial $\mathrm{pCO}_{2}$ to normal: An increase from just 5 to $7 \mathrm{~L} /$ minute will restore normocapnia (assuming no other changes have occurred or abnormalities exist as ventilation is increased), even when the shunt is $60 \%$ of the cardiac output.

Fourth, $\dot{\mathrm{V}}_{\mathrm{A}} / \mathrm{Q}$ inequality is generally a cause of greater physiological dead space than shunt is (Figure 1) (calcula-

$\mathrm{CO}_{2}=$ carbon dioxide; $\log \mathrm{SDQ}=$ second moment (dispersion) of the ventilation/perfusiondistribution on a log scale; $\mathrm{pCO}_{2}=$ partial pressure of carbon dioxide; $\dot{\mathrm{V}}_{\mathrm{A}} / \dot{\mathrm{Q}}=$ ventilation/perfusion ratio. 
Figure 1
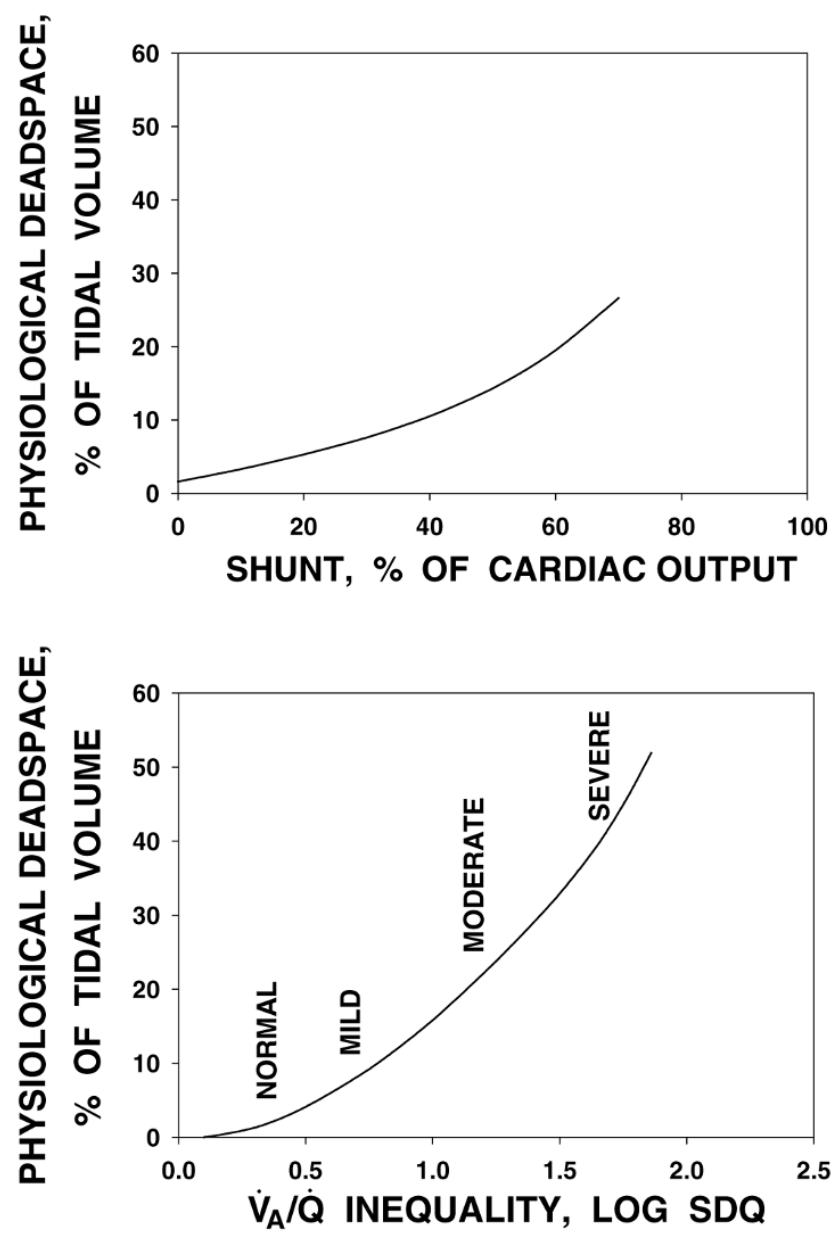

Comparison of effects of shunt (top) and ventilation/perfusion ratio $\left(\dot{V}_{A} / \dot{Q}\right)$ inequality (bottom) on calculated physiological dead space. In general, $\dot{V}_{A} / \dot{Q}$ inequality leads to greater dead space than shunt does. Log SDQ, second moment (dispersion) of the ventilation/perfusion distribution on a log scale

tions using algorithms from [2]). For example, it takes a very large, $60 \%$ shunt to increase dead space by $20 \%$ but a lognormal pattern of only moderate $\dot{\mathrm{V}}_{\mathrm{A}} / \mathrm{Q}$ inequality $(\log \mathrm{SDQ}=$ 1.3) does the same. Normal log SDQ is less than 0.6 [5], and the highest log SDQ values seen are about 2 to 2.5. Log SDQ is a parameter defined for quantifying $\dot{V}_{A} / Q$ inequality in the multiple inert gas elimination technique $[6,7]$ and is the second moment (dispersion) of the $\dot{\mathrm{V}}_{\mathrm{A}} / \mathrm{Q}$ distribution on a log scale.

Fifth, Niklason and colleagues show that, for any given value of shunt, additional perturbations commonly seen in the intensive care unit influence arterial $\mathrm{pCO}_{2}$ and therefore will increase calculated dead space. These include a reduction in cardiac output and, separately, acidosis. This also means that a high cardiac output will reduce the dead space effect of shunt, as will alkalosis. The clinical message is that observed changes in dead space may reflect changes in cardiac output or acid/base state rather than changes in the shunt itself.

In summary, the calculations of Niklason and colleagues serve to point out the complexity of gas exchange in critical illness and the challenges we face in trying to interpret apparently simple measurements as indicators of the lung's ability to carry out its primary responsibility-gas exchange.

\section{Competing interests}

The author declares that he has no competing interests.

\section{References}

1. Niklason L, Eckerstrom J, Jonson B: The influence of venous admixture on alveolar dead space and $\mathrm{CO}_{2}$ exchange in ARDS: computer modelling. Crit Care 2008, 12:R53.

2. West JB: Ventilation-perfusion inequality and overall gas exchange in computer models of the lung. Respir Physiol 1969, 7:88-110.

3. Mecikalski MB, Cutillo AG, Renzetti AD Jr.: Effect of right-to-left shunting on alveolar dead space. Bull Eur Physiopathol Respir 1984, 20:513-519.

4. Riley RL, Cournand A: 'Ideal' alveolar air and the analysis of ventilation/perfusion relationships in the lung. J App/ Physiol 1949, 1:825-847.

5. Wagner PD, Hedenstierna G, Bylin G: Ventilation/perfusion inequality in chronic asthma. Am Rev Respir Dis 1987, 136: 605-612.

6. Wagner PD, Saltzman HA, West JB: Measurement of continuous distributions of ventilation/perfusion ratios: theory. J App/ Physiol 1974, 36:588-599.

7. Evans JW, Wagner PD: Limits on $\dot{\mathrm{V}}_{\mathrm{A}} / \mathrm{Q}$ distributions from analysis of experimental inert gas elimination. J Appl Physiol 1977, 42:889-898. 